\section{Hepatitis B and HIV co-infection is still treated using lamivudine-only antiretroviral} therapy combination in Uganda

Ponsiano Ocama ${ }^{1}$, Emmanuel Seremba ${ }^{2}$, Betty Apica ${ }^{2}$, Kenneth Opio

1. Makerere University College of Health Sciences, Department of Medicine,

Gastroenterology Division, Mulago Hospital, Kampala, Uganda

2. Mulago National Hospital, Division of gastroenterology, Kampala, Uganda

3. Gulu University Medical School, Gulu, Uganda

\section{Abstract}

Background: Hepatitis B virus (HBV) and HIV are endemic in Uganda. Co-infection is common and leads to rapid progression of liver disease. Burden of co-infection is unknown yet most patients are on lamivudine-only ART where resistance is frequent. Most patients are initiated on antiretroviral therapy (ART) without knowing their HBV status.

ance is frequent. Most patients are initiated on antiretroviral therapy (ART) without knowing their HBV status.
Objectives: To determine burden of co-infection and HBV viral suppression among patients on ART in NorthernUganda. Methods: We recruited HIV infected adult patients on ART in a cross-sectional study. Age, sex, ART regimen and duration were recorded. Hepatitis B surface antigen ( $\mathrm{HBsAg}$ ), hepatitis B core antibody (anti-HBcAb) and liver panel were performed. For those $\mathrm{HBsAg}+$, hepatitis B e antigen ( $\mathrm{HBeAg}$ ) and $\mathrm{HBV}$ DNA were performed. $\mathrm{CD} 4$ cell count was recorded. Results: Three hundred patients were recruited. Twenty $(6.7 \%)$ were co-infected, while $41 \%$ were anti-HBcAb+. Overall $188(62.7 \%)$ were on lamivudine- only HBV active drug. Median ART duration 2 years (IQR 1-5), mean CD4+ cell count 317 cells/microlitre (SD 255-557). Of $20 \mathrm{HIV/HBV} \mathrm{co-infected,} \mathrm{11/20} \mathrm{(55 \% )} \mathrm{were} \mathrm{on} \mathrm{lamivudine-only} \mathrm{ART,} \mathrm{median}$ duration 1.5 years. Nineteen $(95 \%)$ had undetectable HBV DNA. Seventeen $(85 \%)$ were HBeAg negative. Mean CD4+ cell count 327 cells/microlitre (SD 197-482).

Conclusion: A large proportion of patients were on lamivudine- only HBV-active ART. Resistance may occur long term Conclusion: A large proportion of patients were on lamin
thus testing for HBV and correct ART is recommended

Key words: HIV, HBV, Co-infection, Treatment

DOI: http://dx.doi.org/10.4314/ahs.v15i2.4

\section{Introduction}

Hepatitis B virus (HBV) infection is common in Uganda with a national prevalence of $10 \%$ reported in 2009 However, the epidemiology varies considerably in the different regions in Uganda. The Northern region has the highest prevalence of between $20 \%$ to $25 \% .{ }^{1}$ On the other hand human immune deficiency virus (HIV) is also endemic in Uganda with a national average of $7.3 \%$.The two viruses share modes of transmission, thus co-infection is expected to be high. Previous studies in Uganda have reported co-infection rates of $10 \%$ to $23 \% 0^{2,3}$

\section{Corresponding author:}

Ponsiano Ocama

Makerere University College of Health sciences

P.O.Box 7072

Kampala, Uganda

Email: ponsiano.ocama@gmail.com
Human Immmune deficiency virus (HIV) infection is associated with rapid progression of liver disease in persons who are co-infected with HBV. This is even more relevant currently when antiretroviral therap (ART) has improved life expectancy for patients with HIV even in resource limited settings. This situation has led to liver disease becoming one of the most important causes of early death among the HIV infected individuals in the Western world. ${ }^{4-6}$ Even where treatment and monitoring is widely available, liver disease still accounts for up to $20 \%$ of deaths in HIV positive patients. ${ }^{7}$ In the areas most affected by HBV and HIV infections, high co-infection rates worsen the prognosis logical conversion and viral clearance have been shown to be lower in patients co-infected with HIV, leading to accelerated rates of progression to cirrhosis. ${ }^{8}$

Lamivudine, tenofovir and emtricitabine, used in HIV infection are as well effective against HBV. Use of these drugs in the overall ART combination has led to significant improvement in outcome of co-infected pain dually infected individuals. Rates of hepatitis B sero- tients. However, resistance to lamivudine (and emtricitabine) occurs very frequently. In co-infected patients the incidence of resistance reaches up to $90 \%$ over 5 years of treatment. ${ }^{9}$ Resistance will lead to reversal of the gains achieved by using ART. All the complications that occur in co-infected patients who are not on ART will become tenable when lamivudine resistance occurs. Tenofovir however, has not shown significant resistance over 5 years of use in co-infected patients. ${ }^{10} \mathrm{An}$ ART combination containing tenofovir+ lamivudine or tenofovir+ emtricitabine is recommended in co-infected patients. ${ }^{4,11,12}$ Such guidelines are not in existence in most sub-Saharan African countries despite the latter carrying the highest burden of co-infections worldwide. This could partly be because of lack of evidence of resistance patterns.

Unfortunately since most of our patients are initiated on therapy without testing for HBV and majority have been on lamivudine monotherapy (for HBV in co-infected patients) inadvertently there may be a lot of resistance in the patient population especially where the burden of both infections is high. Hepatitis $\mathrm{B}$ viral loads and liver function tests may be indicators of resistance and possible HBV flares. In this study we determined the burden of co-infection and HBV viral suppression among patients who have already been on ART in the Northern part of Uganda which carries a high burden of HBV and HIV.

\section{Patients and methods}

We conducted a cross-sectional study among patients attending the HIV clinic in Gulu regional referral hospital. At the time we started data collection this clinic, had 1,744 patients active on ART. Close to 200 clients attend the clinic everyday and most of the patients were on ART combinations containing either zidovudine/ lamivudine or tenofovir/lamivudine in addition to nevirapine or efavirenz as first line combinations. A few patients were on alluvia with any of the above combinations for second line.

All patients attending the clinic who where 18 years or more and on ART were eligible to participate in the study. They were recruited after signing informed consent document. Because of the large numbers, we recruited the first 20 patients who fulfilled the eligibility criteria on each clinic day as long as the participant had not been recruited before in this study. collected data on age, sex, marital status, widow or widower as well as clinical information: history of yellow eyes, family history of liver diseases, ART regimen and duration on ART, any other drugs. We drew 10 milliliters of venous blood for further investigations, divided into purple top and red top containers, each carrying 5 milliliters. We performed hepatitis B surface antigen (HBsAg) test using HBsAg card (Cypress Diagnostics, Langdorp, Belgium) using a drop of whole blood. Results of these tests were read in 20 minutes and reported as positive or negative. The remaining samples were then transported to the main laboratory where further testing was performed. For all patients, liver panel was performed using Eon one chemistry analyzer (Viral Diagnostics, Victoria, Australia), with reagents from $\mathrm{Cy}$ press Diagnostics (Langdorp, Belgium). The upper limit of normal (ULN) for alanine aminotransferase (ALT) and aspartate aminotransferase (AST) was $40 \mathrm{IU} / \mathrm{mL}$.

On the other hand ULN for total Bilirubin, albumin, total protein, gamma glutamyl transferase, and alkaline phosphatase (ALP) were reported as 17 micromol/L $50 \mathrm{~g} / \mathrm{L}, 83 \mathrm{~g} / \mathrm{L}, 54 \mathrm{U} / \mathrm{L}$ and $125 \mathrm{U} / \mathrm{L}$ respectivey. In addition, hepatitis $\mathrm{B}$ core antibody ( $\mathrm{HBcAb}$ ) was performed on all patients while $\mathrm{HBeAg}$ testing was done on samples that had initially tested positive for $\mathrm{HBsAg}$. The testing for $\mathrm{HBcAb}$ and $\mathrm{HBeAg}$ were done using Biomeriuex miniVidas automated immunoassay analyzer (Biomerieux, Marcy l'Etoile, France). The same HBsAg positive samples were subjected to HBV DNA testing using real time polymerase chain reaction (RT PCR) using COBAS AmpliPrep/COBAS TaqMan HBV Test, v2.0 by Roche, with a lower limit of quantification (LLOQ) of $20 \mathrm{IU} / \mathrm{mL}$. Patients were requested to allow use of their $\mathrm{CD} 4$ cell count results performed routinely in this clinic

HBV viral loads was deemed to have been suppressed if it was below the lower limit of quantification of 20 $\mathrm{IU} / \mathrm{mL}$.

The study was approved by School of Medicine Research Ethics committee of Makerere University as well as the Uganda National Council for Science and Technology.

Data was entered in a Microsoft access program and exported to stata- version 12 for analysis. The prevalence of $\mathrm{HBV}$ infection was expressed as proportion of those who tested HBsAg positive in the total pop- 
ulation recruited. Comparison of liver panel among ly of young patients with a median age of 36.5 years, in $<0.05$ were considered significant.

\section{Results}

In the months of May and June 2013, three hundred patients were recruited in the study, composed mainitive for $\mathrm{HBsAg}$ while $41 \%$ were exposed to hepatitis B (anti-HBcAb positive). All patients were on AR'T of whom $188(62.7 \%)$ were on lamivudine as the only drug active on $\mathrm{HBV}$ in the ART combination and 110 $(36.7 \%)$ were on a combination of lamivudine plus tenofovir. Overall, patients had been on ART for a median duration of 2 years (IQR 1-5) and their mean $\mathrm{CD} 4+$ cell count was 317 cells / $\mu \mathrm{L}$ (SD 197-482).

Table 1. Baseline characteristics of HIV infected patients on ART attending Gulu Regional referral hospital Infectious Diseases Clinic, 2013 ( $(\mathrm{N}=300)$

\begin{tabular}{|c|c|}
\hline \multicolumn{2}{|l|}{ Parameters } \\
\hline Age; years (median) & $36.5(10.6)$ \\
\hline Gender; Female n (\%) & $224(74.7)$ \\
\hline ART regimen distribution* & \\
\hline Lamivudine $(\%)$ & $188(62.7)$ \\
\hline Tenofovir $(\%)$ & $2(0.6)$ \\
\hline Lamivudine+Tenofovir, $\mathrm{n}(\%)$ & $110(36.7)$ \\
\hline Tenofovir +Emtricitabine $\left(\right.$ Truvada $\left.^{\mathrm{TM}}\right), \mathrm{n}(\%)$ & $0(0))$ \\
\hline Duration on ART median(IQR) years & $2(1-5)$ \\
\hline CD4 count (mean) cells $/ \mu \mathrm{L}$ & $317(197-482)$ \\
\hline $\mathrm{HBsAg}+, \mathrm{n}(\%)$ & $20(6.7)$ \\
\hline $\mathrm{HBcAb}, \mathrm{n}(\%)$ & $118(41.0)$ \\
\hline
\end{tabular}

*This lists only drugs active against HBV in the ART regimen. Patients were on complete ART combinations

Table 2 describes demographic, clinical and laboratory these patients had undetectable HBV viral loads ove characteristics of the 20 patients who were co-infected this median duration of treatment. Seventeen $(85 \%)$ with HBV. Most of these patients, 11/20 (55\%) were patients had the hepatitis B e antigen negative chronic on lamivudine only ART and they had been on ART HBV type. In general, the mean CD4+ cell count of for a median duration of 1.5 years. Nineteen (95\%) of the 20 patients was 327 cells / $\mu \mathrm{L}$ (SD 255-557) and liver enzymes (ALT, AST) were within normal limits.

Table 2 Demographic, clinical and laboratory characteristics of HBV HIV infected patients attending the Gulu HIV clinic 2013, $(\mathrm{N}=20)$

\begin{tabular}{|l|l|l|}
\hline Parameters & No & Percent \\
\hline Age; median (IQR) & $30.5(27.5-39)$ & \\
\hline Gender; Female & 19 & 95 \\
\hline ART regimen distribution* & & 55 \\
Lamivudine & 11 & 0 \\
Tenofovir & 0 & 45 \\
Lamivudine+Tenofovir & 9 & 0 \\
Tenofovir+Emtricitabine & 0 & \\
\hline Median duration on ART, years (IQR) & $1.5(0.75-5.0)$ & \\
\hline Mean CD4 cell count/ $\mu$ L (SD) & $327(255-557)$ & 5 \\
\hline HBeAg negative & $17(85.0)$ & \\
\hline HBV DNA detected & 1 & \\
\hline Mean ALT, U/L (SD) & $26.3(20.6)$ & \\
\hline Mean AST, U/L (SD) & $28.0(12.9)$ & \\
\hline
\end{tabular}

$28.0(12.9)$

*This lists only drugs active against HBV in the ART regimen. Patients were on complete ART combinations

Comparing liver panel between HBsAg-positive and two arms, except for a trend to higher total Bilirubin in $\mathrm{HBsAg}$-negative revealed no statistical difference in the the $\mathrm{HBsAg}$ negative individuals and this is shown on Table 3.

Table 3. Comparison of liver panel among HIV infected patients with (HBsAg+) and without (HBsAg-) Hepatitis B infection in Gulu HIV clinic, 2013

\begin{tabular}{|l|l|l|l|}
\hline Variable & HBsAg- & HBsAg+ & P-value \\
\hline Albumin: mean(SD), g/l & $42(0.46)$ & $43(4.1)$ & 0.4419 \\
\hline ALP: median (IQR), U/L & $83(68-99)$ & $92(76-109)$ & 0.2015 \\
\hline GGT: median (IQR), U/L & $33(24-56)$ & $45(29-84)$ & 0.1265 \\
\hline Bilirubin: mean (SD) $\mu \mathrm{L}$ & $85.0(56.1)$ & $57.8(18.7)$ & 0.0560 \\
\hline Protein: mean (SD) g/L & $74(0.81)$ & $73(7.3)$ & 0.7404 \\
\hline CD4 cell count: median (IQR) / $\mu \mathrm{L}$ & $316(190-481)$ & $327(255-557)$ & 0.2945 \\
\hline
\end{tabular}

\section{Discussion}

Our study has demonstrated that most patients in this clinic have been on lamivudine as the only active drug against hepatitis B in HIV infected patients. This has been the trend previously in most clinics in sub-Saharan Africa where most ART combinations were composed either of zidovudine plus lamivudine, or stavudine and lamivudine in addition to either nevirapine or efavirenz. ${ }^{13-15}$ In most patients these treatment regimens were taken without routine screening for hepatitis $\mathrm{B}$ and most regimens did not therefore take HBV into consideration.
In this study we have shown that chronic hepatitis B occurred in $6.7 \%$ of the patients with a level of exposure measured at $41 \%$. These figures are lower than what ha been shown in the general population in this Northern Ugandan region. Bwogi et al, in a study conducted as part of National sero-survey in the year 2004 in Uganda demonstrated a general population prevalence of $21 \%$ in the North Central districts of Uganda where Gulu is located. ${ }^{1}$ Another study conducted in 2009 by Ochola et al in Gulu Municipality in 2009 showed a prevalence of $17 \%$ in the Municipality. ${ }^{16}$ It is not clear whether this is a result of general awareness of the population 
on HBV and the fact that many people have resorted to $\mathrm{HBV}$ vaccination in addition to the early childhood vaccination which was initiated in Uganda in 2002.

Despite the $6.7 \%$ prevalence of HBV and the fact that most patients were on lamivudine as the only drug active against $\mathrm{HBV}$ in the ART combination we have shown that $93.7 \%$ had undetectable viral loads over an average treatment period of 1.5 years. However one patient had detectable viral loads. This was a female patient who was HBeAg negative and had HBV viral loads of $2,464,000 \mathrm{IU} / \mathrm{mL}$ at nine years of lamivudine plus zidovudine combination. The liver enzymes were actually elevated with an ALT level of $95.9 \mathrm{U} / \mathrm{L}$ These findings show that lamivudine-only ART therapy was adequate in suppressing HBV virus in the short run. As treatment duration increases there is likely to be an increasing number of patients presenting with increased viral loads as has been seen in the one patient described above. Although in this study resistance testing was not done, it is likely that this patient already had breakthrough infection with HBV resistance and this could lead to worsening of liver disease. In this patien the elevation of the liver enzymes noted in the study already shows liver cell injury which if not treated adequately would lead to cirrhosis and its complications. We recommended HIV viral loads be performed for this patient and the treatment be changed to include tenofovir.

\section{Limitations}

This study had several limitations. First, because of the cross-sectional nature of the study we could not tell what the HBV viral loads were at initiation of ART. The low HBV viral loads observed in these patients especially in those on lamivudine-only ART could be a result of low viral loads at initiation. Lamivudine is able to cause significant viral suppression in situation of low viral loads at antiviral therapy initiation with limited chance of accumulation of resistance strains. ${ }^{1}$ The possibility of low viral loads at initiation could also be entertained by the fact that most patients were HBeAg negative. We cannot however also tell if the observed HBeAg status was a result of seroconversion. This is however unlikey since sero-conversion is not a common occurrence especially considering the average duration of therapy and the fact that this $\mathrm{HBV}$ is occurring in combination with HIV. ${ }^{4,17,18}$ Also, a previous study in the same lo-
1. Bwogi J, BrakaF, Makumbi I, et al. . Hepatitis B infection is highly endemic in Uganda: findings from a national survey. Afr Health Sci 2009;9:98-108. 2. Ocama P, Kamya M, Piloya T, et al The spectrum of liver diseases in HIV onfected individuals at an HIV treatment clinic in Kampala, Uganda. Afr Health Sci 2008;8:8-12.

3. Weidle PJ, Moore D, Mermin J, et al. Liver enzyme Improve Over Twenty Four Months of First Line Non-Nucleoside Reverse Trancriptase Inhibitor-Based Therapy in Rural Uganda. AIDS Patient Care STDS 2008;10:787-95

4. Sun HY, Sheng WH, Tsai MS, Lee KY, Chang SY, Hung CC. Hepatitis B virus coinfection in human immunodeficiency virus-infected patients: A review. World J Gastroenterol. 2014;20:14598-614.

5. Salmon-Ceron D, Lewden $C$, Morlat P, et al. Liver disease as a major cause of death among HIV infected patients: role of hepatitis $\mathrm{C}$ and $\mathrm{B}$ viruses and alcohol. J Hepatol. 2005;42:799-805.

6. Thio CL, Searberg E, Skolasky R Jr et al HIV-1, hepatitis $\mathrm{B}$ and risk of liver related mortality in the Multicetnter Cohort Study (MACS) Lancet. 2002, 360: 1921

7. Hooshyar D, Hanson DL, Wolfe M, Seliki R, Buskin S, McNaghten A. . Trends in perimortal conditions and mortality rates among HIV-infected patients. AIDS 2007;21:2098-100.

8. Fattovich G, Bortolotti F, Donato F. Natural history of chronic hepatitis B: special emphasis on disease progression and prognostic factors. J Hepatology 2008;48: 335-52.

. Benhamou Y B Bochet M, Thibault V, et al. lamivudine in human immune deficiency virus infected patients. Hepatology 2000;31:1030-31. therapy with amivudine and tenofovir in patients co-infected with HIV-1 and wild type hepatitis B virus. Clin Infect Dis 2004;39(7):1062-64.

11. Lok ASF, McMahon B. Chronic Hepatitis B: Update 2009. Hepatology. 2009;50:1-35.

12. Wiersma ST, McMahon B, Pawlotsky JM, et al. Treatment of chronic hepatitis B virus infection in reource-constrained settings: expert panel consensus. Liver Int. 2010;31:755-61.

13. Coetzee D, Hildebrand K, Boulle A. et al Outcomes after Two Years of Providing Antiretroviral Treatment in Khavelitsha, South Africa. AIDS. 2004;18:887-95.

14. Djomand G, Roels T, Ellerbrock T., et al. Virologic and Immunologic Outcomes and Programmatic Challenges of an Antiretroviral Treatment Pilot Project in Abidjan, Côte d'Ivoire. . AIDS. 2003;17:S5-S15.

15. Wester CW, Kim S, Bussmann H., et al. Initial Response to Highly Active Antiretroviral Therapy in HIV1C Infected Adults in a Public Sector Treatment Program in Botswana. Journal of Acquired Immune Deficiency Syndrome. 2005;40:336-43.

16. Ochola E, Ocama P, Orach CG, et al. High burden of hepatitis B infection in Northen Uganda: Results of a population-based survey. BMC Public Health. 2013;13:727.

17. Soriano V, de Mendoza C, Fernández-Montero JV, Labarga P, Barreiro P. Management and treatment of chronic hepatitis B in HIV-positive patients. Ann Med. 2014;46:290-6.

18. Kang M, Hollabaugh K, Pham V, Koletar SL, Wu $\mathrm{K}$, Smurzynski M, Aberg JA. Virologic and serologic disease progression and outcome as seen in the one patient. Treatment with tenofovir in combination with avoid this outcome

\section{of Interest:}

The authors do not have any conflict of interest to de-

\section{Acknowledgement}

The work was supported by Training Health Researchers into Vocational Excellence (THRiVE) in East Afria, grant number 087540 , funded by We

We also acknowledge Dr Francis Pebalo of Gulu HosAliker for the laboratory work performed in the study. 